\title{
Comparison of vasodilator drug prazosin with digoxin in aortic regurgitation ${ }^{\star}$
}

\author{
BERNARD E F HOCKINGS, GEOFFREY D COPE, GEOFFREY M CLARKE, \\ ROGER R TAYLOR
}

From the Departments of Cardiology and Intensive Care, Royal Perth Hospital, Perth, Western Australia

SUMMARY Intravenous administration of the vasodilator sodium nitroprusside has beneficial haemodynamic effects in subjects with severe aortic regurgitation while acute digitalisation can produce unwanted effects associated with an increase in systemic vascular resistance. This study compares the haemodynamic effects of the vasodilator prazosin and digoxin in eight patients with isolated severe aortic regurgitation. Prazosin $5 \mathrm{mg}$ orally resulted in a $12 \pm 3$ (SE) per cent increase in cardiac index (thermodilution), maintained over four to six hours, while digoxin $0.75 \mathrm{mg}$ intravenously did not change the cardiac index. Prazosin reduced mean arterial pressure by $9 \pm 3 \mathrm{mmHg}$ and systemic vascular resistance by $18 \pm 4$ per cent while digoxin resulted in a $6 \pm 2$ per cent increase in the latter. Mean pulmonary capillary wedge pressure fell $3 \mathrm{mmHg}$ with prazosin. In this group of patients with severe aortic regurgitation but without severe cardiac failure, the changes with either drug, studied in doses conventionally used, were small but those with prazosin were directionally more desirable than those resulting from digoxin.

This study describes and compares the haemodynamic effects of the orally active vasodilator drug prazosin and digoxin in a group of patients with severe chronic aortic regurgitation.

Corrigan, ${ }^{1}$ writing in 1832 , believed that when digitalis glycosides were administered in the treatment of heart failure resulting from aortic regurgitation, the patients were "always worse". He attributed the harmful effects he observed to bradycardia which "allowed more time for regurgitation". In 1908, Stewart ${ }^{2}$ predicted harmful effects from digitalis in aortic regurgitation because of a rise in the systemic vascular resistance. Objective evidence of the haemodynamic effects of the digitalis glycosides in the presence of aortic regurgitation is sparse. Kloster and associates ${ }^{3}$ found that ouabain resulted in a fall in cardiac output in patients with aortic regurgitation without cardiac failure while Hopkins and Taylor $^{4}$ found that ouabain and acetylstrophanthidin increased the regurgitant fraction in dogs with experimentally

* Supported in part by grants from the National Heart Foundation of Australia and the Royal Perth Hospital Research Foundation. Received for publication 26 November 1979 induced aortic regurgitation.

In contrast, the intravenous administration of the vasodilator sodium nitroprusside has been shown to produce distinct haemodynamic improvement in patients with severe aortic regurgitation. Nitroprusside exerts a beneficial effect by decreasing both preload and afterload, the latter resulting in an increase in forward cardiac output and frequently a reduction in the regurgitant fraction..$^{5}$

Notwithstanding this, digitalis glycosides are frequently used in the treatment of patients with aortic regurgitation, sometimes even before overt signs of cardiac failure develop. Theoretically at least, an orally acting vasodilator drug could be a more rational approach to the treatment of such patients. Prazosin is a vasodilator agent which is available in oral form and which possesses properties similar to those of sodium nitroprusside, acting on both the capacitance and resistance vascular beds. While prazosin has been used in the management of patients with resistant cardiac failure, ${ }^{89}$ the effects of the drug on the circulation of patients with aortic regurgitation have not previously been described. 


\section{Subjects and methods}

Eight patients, seven men and one woman, consented to the study. Their mean age was 46 years. They all had chronic severe isolated aortic regurgitation documented clinically and by cardiac catheterisation and aortography. Five patients had a history of probable rheumatic fever and one patient had pathological evidence of cystic medial necrosis in the aortic valve when it was subsequently excised. The aetiology of the aortic regurgitation in the other two patients is unknown. Selective coronary angiography showed the absence of obstructive coronary artery disease in all subjects. No patient had previous cardiac surgery and though all were candidates for, and subsequently underwent, aortic valve replacement, no patient was deemed to be critically ill at the time of study. All were in sinus rhythm; other details are shown in Table 1. One patient was in New York Heart Association (NYHA) class I, four patients were in class II, and three were in class III. Three patients were not taking any medication, one was taking digoxin alone, two were taking diuretics alone, and two were taking both digoxin and diuretics.

Patients were admitted to the coronary care unit for study. When treatment included digoxin, this was stopped one week before, while all other drugs were withheld for at least 24 hours. A 20 gauge Teflon catheter was inserted into a radial artery and used to record systemic arterial pressure. Right atrial, pulmonary arterial, and pulmonary capillary wedge pressures were obtained using a $7 \mathrm{~F}$ balloon tipped thermodilution flotation catheter (Edwards Laboratories Inc), which was inserted percutaneously. Pressures were measured using Bentley 800 transducers (Bentley-Trantec Inc), and were displayed on a multichannel recorder (Irex Medical Systems). Cardiac output was measured by thermodilution (Edwards Laboratories Inc) using iced 5 per cent dextrose, the measurement being taken as the mean of three readings having less than 10 per cent variation between them. Echocardiograms were obtained using a Smith Kline Ekoline 20A and a $2.5 \mathrm{MHz}$ transducer (Smith Kline Instruments Inc). Standard techniques for recordings and measurements were used. ${ }^{10}$ Echocardiograms of suitable quality for accurate measurement of left ventricular dimensions were obtained in six out of the eight patients. Measurements were made by an observer unaware of the relation of the timing of the recording to the administration of the drugs.

Patients were studied in the postabsorptive state. After baseline haemodynamic measurements and an echocardiogram had been obtained, the subjects were given prazosin $1 \mathrm{mg}$ orally and observations were repeated an hour later. Recording cannulae were left in place, and the next morning $5 \mathrm{mg}$ prazosin was given after control observations. Pressure and cardiac output measurements were repeated at 30-minute intervals for two hours and then hourly up to six hours. An echocardiogram was obtained during the period of maximal haemodynamic effect of the drug, one-and-a-half to two hours after administration. On the third day, after control observations, digoxin (Burroughs Wellcome) $0.75 \mathrm{mg}$ was given intravenously over 10 minutes. Pressures and cardiac output were measured at hourly intervals for six hours and echocardiography was repeated when maximal haemodynamic effects of the drug were apparent, approximately three hours after administration.

Derived haemodynamic indices were calculated as follows: systemic vascular resistance (SVR dynes $\left.\mathrm{s} \mathrm{cm}^{-5}\right)$ from $((\overline{\mathrm{AP}}-\overline{\mathrm{RA}}) \times 80) / \mathrm{CO}$; where $\overline{\mathrm{AP}}$ is mean radial arterial pressure, $\overline{\mathrm{RA}}$ is mean right atrial pressure, 80 is the conversion factor for converting units of resistance into dynes, and $\mathrm{CO}$ is cardiac output; pulmonary vascular resistance (PVR dynes $\left.\mathrm{s} \mathrm{cm}^{-5}\right)$ from $((\overline{\mathrm{PA}}-\overline{\mathrm{PCW}}) \times 80) / \mathrm{CO}$;

Table 1 Eight patients with aortic regurgitation-clinical information

\begin{tabular}{|c|c|c|c|c|c|}
\hline Patient & Age (y) & Symptoms & $\begin{array}{l}\text { NYHA* } \\
\text { classification }\end{array}$ & $\begin{array}{l}\text { Duration of aortic } \\
\text { regurgitation }(y)\end{array}$ & Drugs daily \\
\hline $\begin{array}{l}\text { Male } \\
\text { Male } \\
\text { Male } \\
\text { Male } \\
\text { Male } \\
\text { Male } \\
\text { Female }\end{array}$ & $\begin{array}{l}37 \\
22 \\
53 \\
59 \\
49 \\
36 \\
49\end{array}$ & $\begin{array}{l}\text { Dyspnoea } \\
\text { Dyspnoea, chest pain } \\
\text { Dyspnoea, chest pain } \\
\text { Dyspnoea, chest pain } \\
\text { Dyspnoea } \\
\text { Nil } \\
\text { Dyspnoea, chest pain }\end{array}$ & $\begin{array}{r}\text { II } \\
\text { II } \\
\text { II } \\
\text { III } \\
\text { III } \\
\text { I } \\
\text { III }\end{array}$ & $\begin{array}{l}24 \\
\text { Unknown } \\
\text { Unknown } \\
43 \\
\text { Unknown } \\
23 \\
42\end{array}$ & $\begin{array}{l}\text { Digoxin } 0.5 \mathrm{mg} \\
\text { Nil } \\
\text { Nil } \\
\text { Frusemide } 40 \mathrm{mg} \\
\text { Frusemide } 40 \mathrm{mg} \text {, digoxin } 0.25 \mathrm{mg} \\
\text { Nil } \\
\text { Hydrochlorothiazide } 100 \mathrm{mg} \text {, } \\
\text { amiloride hydrochloride } 10 \mathrm{mg} \text {, } \\
\text { digoxin } 0.25 \mathrm{mg}\end{array}$ \\
\hline Male & 59 & Dyspnoea, chest pain & II & 32 & Cyclopenthiazide $0.5 \mathrm{mg}$ \\
\hline
\end{tabular}

ॠNew York Heart Association classification. 
where $\overline{\mathrm{PA}}$ is mean pulmonary arterial pressure and $\overline{\mathrm{PCW}}$ is mean pulmonary capillary wedge pressure; stroke work index (SWI $\mathrm{g} \mathrm{m}$ per $\mathrm{m}^{2}$ ) from ( $\overline{\mathrm{AP}}$ $\overline{\mathrm{PCW}}) \times(\mathrm{CI} / \mathrm{HR}) \times 0.0136$ when $\mathrm{CI}$ is cardiac index and HR is heart rate.

For statistical analysis changes induced by each drug were expressed as percentage changes and the significance of each mean percentage change was evaluated using Student's $t$ test rather than using analysis of paired comparisons in individual patients.

\section{Results}

There were no relevant side effects from either digoxin or prazosin, and all the patients who entered the study were able to complete it. No untoward effects were apparent from stopping digoxin a week before study in those patients on the drug.

Results of prazosin and digoxin administration are summarised in Table 2. Maximum effects of prazosin $5 \mathrm{mg}$ were present at one-and-a-half to two hours and of digoxin at three hours and these are the results presented in this Table. The time course of changes in cardiac index, mean pulmonary capillary wedge pressure, mean arterial pressure, systemic vascular resistance, and heart rate produced by the two drugs is illustrated in the Fig.

Prazosin $5 \mathrm{mg}$ resulted in a fall in systemic vascular resistance of 18 per cent $(p<0.005)$ and a smaller fall in systemic arterial pressure since cardiac index rose 12 per cent $(p<0.005)$. Mean pulmonary capillary wedge pressure fell and though this fall was only $3 \mathrm{mmHg}$ it was significant $(p<0.01)$. Heart rate increased 4 beats $/ \mathrm{min}$ while changes in pulmonary vascular resistance, central venous pressure, and stroke work were not significant. There were no significant differences between the effects of the first dose of prazosin $1 \mathrm{mg}$ and the second of $5 \mathrm{mg}$.

In contrast to the results with prazosin, digoxin increased systemic vascular resistance 6 per cent $(\mathrm{p}<0.05)$ and there was no change in cardiac index (Table 2$)$. Heart rate slowed 6 beats $/ \min (p<0.01)$. There was a small fall in pulmonary capillary wedge pressure which was not significant.

Echocardiograms of suitable quality were obtained in six out of eight patients. All six patients had distinctly increased left ventricular end-diastolic dimensions and in three of the six the fraction of shortening was less than 25 per cent. There was no significant change in end-diastolic dimension or fractional shortening after either prazosin $5 \mathrm{mg}$ or digoxin $0.75 \mathrm{mg}$.

Three of the eight patients had pulmonary capillary wedge pressures greater than $15 \mathrm{mmHg}$. two of these also having fractional shortening less than 25 per cent, but the results in these patients with evidence of depression of left ventricular function were not obviously different from those of the other patients.

\section{Discussion}

The magnitude of regurgitation through an incompetent aortic valve depends not only upon the pathology of the valve but also upon other circula-

Table 2 Haemodynamic changes with prazosin and digoxin in patients with aortic regurgitation

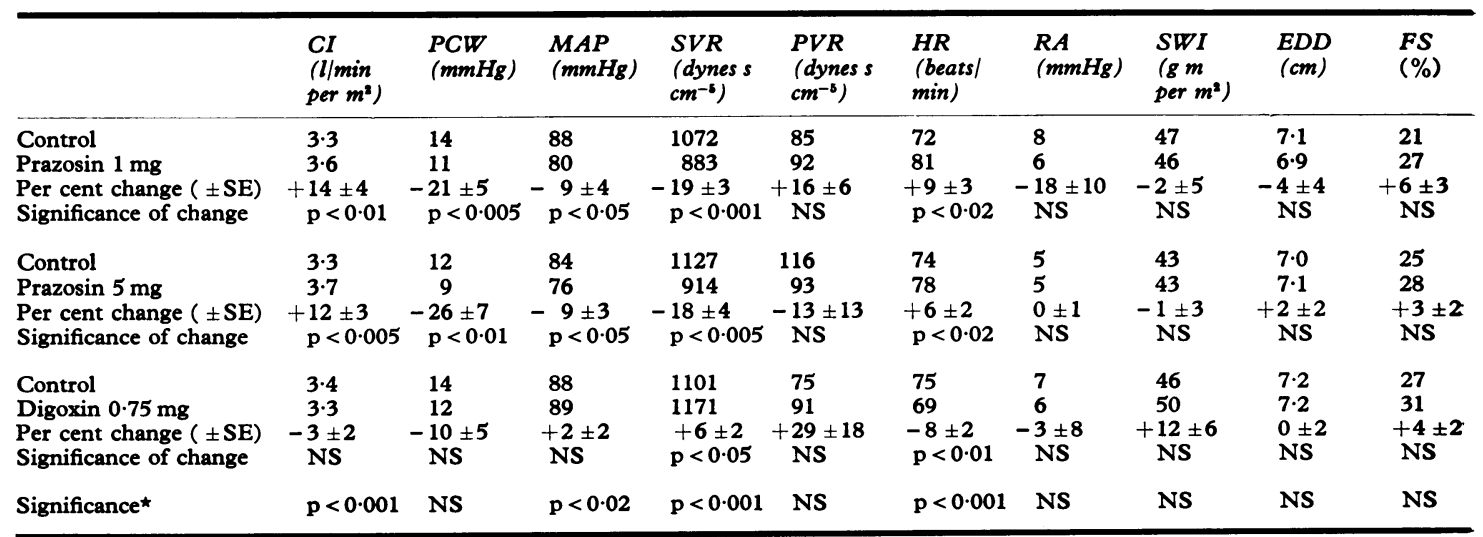

CI, cardiac index; PCW, pulmonary capillary wedge pressure; MAP, mean radial arterial pressure; SVR, systemic vascular resistance; PVR, pulmonary vascular resistance; HR, heart rate; RA, right atrial pressure; SWI, stroke work index; EDD, end-diastolic dimension; FS, fraction of shortening; SE, standard error; NS, not significant.

$\star$ Significance between group mean changes induced by prazosin $5 \mathrm{mg}$ and digoxin $0.75 \mathrm{mg}$. 
tory variables, including the diastolic pressure gradient across the valve and the duration of diastole. ${ }^{11-13}$ The decrease in systemic vascular resistance produced by drugs such as isoprenaline and glucagon has been shown to decrease regurgitant
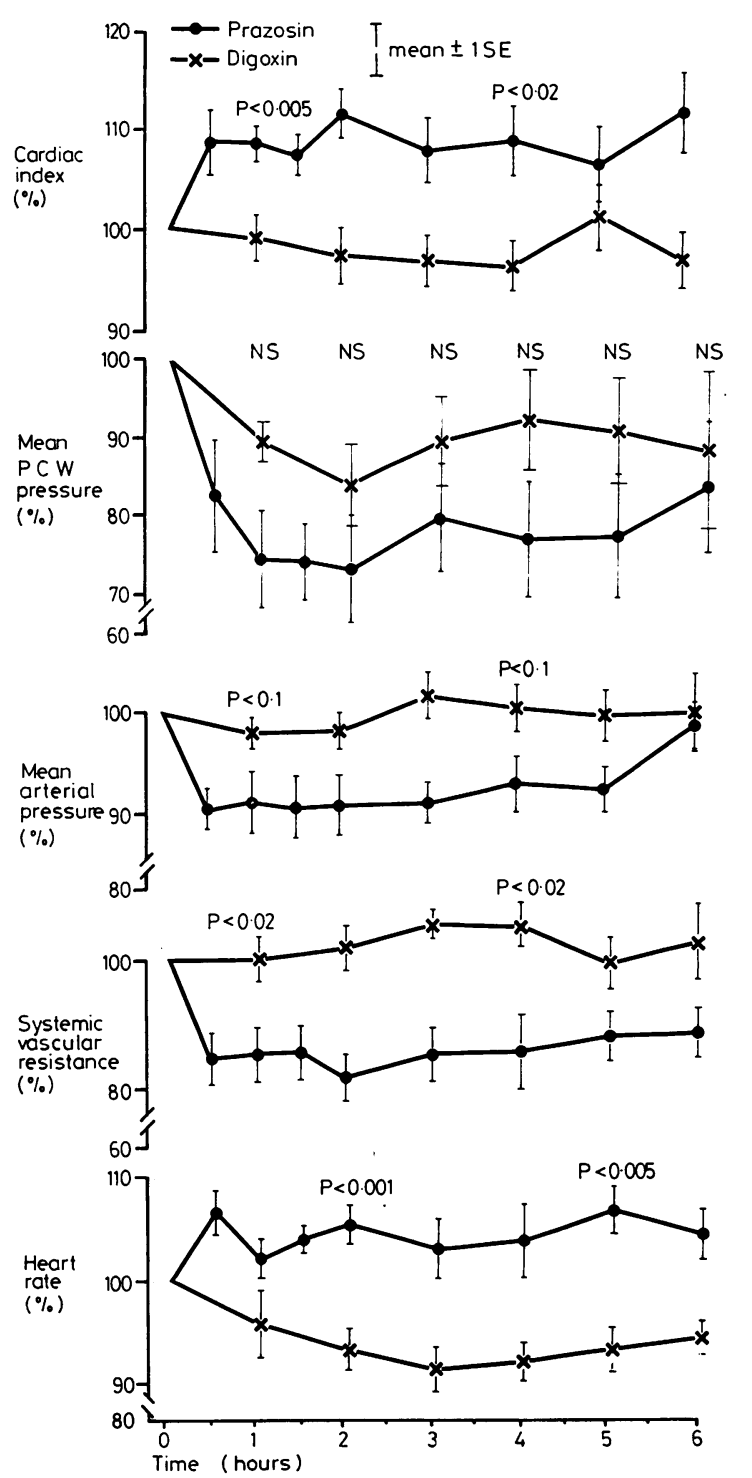

Fig. Haemodynamic changes after prazosin and digoxin. The time course of haemodynamic changes after a single tablet of prazosin $5 \mathrm{mg}$ and a single intravenous injection of digoxin $0.75 \mathrm{mg}$ in the eight patients with chronic aortic regurgitation. Average values $\pm S E M$ are shown; $p$ values shown on the figure relate to the significance of difference between group mean measurements after prazosin and digoxin. fraction under experimental conditions allowing accurate measurement of ascending aortic blood flow. ${ }^{414}$ Reduced impedance enhances forward flow, and regurgitant flow diminishes concurrently if the diastolic aorto-ventricular pressure gradient is reduced. In human subjects with aortic regurgitation, intravenous sodium nitroprusside, which produces dilatation of both the systemic resistance and capacitance beds, has been shown to reduce left ventricular end-diastolic pressure and volume, to increase forward cardiac index and ejection fraction, and frequently to reduce aortic regurgitant fraction. Vasodilator therapy with nitroprusside has become established as one of the most effective forms of temporary medical treatment before valve replacement in the critically ill patient with aortic regurgitation. ${ }^{56}$ Since prazosin, a post-synaptic alpha-adrenergic blocker, also acts on resistance and capacitance beds, but can be administered orally, and is effective in the management of patients with resistant cardiac failure,$^{8915}$ it was considered important to document some of the haemodynamic effects of prazosin in patients with severe aortic regurgitation. Prazosin reduced systemic vascular resistance 18 per cent, increased cardiac index 12 per cent, and led to a small fall in pulmonary capillary wedge pressure. These changes were not associated with consistent changes in left ventricular dimensions measured echocardiographically.

The patients studied had severe but chronic stable aortic regurgitation and the results cannot be extrapolated directly to other groups. It is now widely appreciated that dilatation and hypertrophy allow compensation in terms of resting left ventricular end-diastolic pressure and cardiac output until late in the natural history of chronic aortic regurgitation. Though our patients as a group were quite symptomatic, only three had abnormal mean pulmonary capillary wedge pressures which, in this situation, probably indicate some depression of myocardial function. ${ }^{16}$ The haemodynamic situation in acute torrential regurgitation is often quite different, with pronounced rises in left ventricular end-diastolic pressure, premature mitral valve closure, and circulatory failure.

We studied the effects of digoxin because digitalis is frequently given to patients with severe aortic regurgitation despite the absence of obvious cardiac failure or atrial fibrillation. The little objective evidence available has actually suggested that there might be a deleterious effect in patients such as those studied. In the dog with aortic regurgitation, acute digitalisation increases systemic vascular resistance and regurgitant flow. Despite the positive inotropic effect of the glycosides, left ventricular end-diastolic pressure increases. ${ }^{4}$ In 
patients with chronic aortic regurgitation and without cardiac failure Kloster and associates ${ }^{3}$ found that intravenous ouabain resulted in an increase in systemic vascular resistance and a decrease in resting cardiac output, with only a trivial fall in left heart filling pressures. In this present study digoxin was given intravenously to ensure that a known quantity of the drug was active at the time of haemodynamic monitoring. Cardiac glycosides have been shown to have different effects on systemic vascular resistance and arterial pressure depending on the rate of intravenous infusion. ${ }^{17}$ Early after the intravenous administration of some cardiac glycosides the increase in systemic vascular resistance may precede direct cardiac effects. ${ }^{17}$ This, however, is not relevant to the observations three hours after intravenous digoxin when the cardiac inotropic effect would be expected to be maximal. ${ }^{18}$ There are no important differences between slow intravenous and acute oral administration but it is possible that there are differences in effects between acute and chronic treatment. In this study we were particularly interested in the effects of digoxin at times greater than one hour after drug administration when haemodynamic indices are not affected by the rate of intravenous administration and changes parallel the effects of orally administered glycosides. We did not find any evidence of a harmful effect but the beneficial effect was minimal. Nevertheless, in patients with obvious cardiac failure digitalis may reduce rather than increase systemic vascular resistance, ${ }^{19}$ and we emphasise again that the effects of digitalis in patients with aortic regurgitation and severe cardiac failure are unknown.

This study was confined to relatively simple measurements under resting conditions without any attempt to measure regurgitant flow. Other constraints were imposed by ethical considerations; for example, digoxin was always administered after prazosin. This was accepted because of the relatively short plasma half life of prazosin, two-and-a-half to four hours, ${ }^{20}$ and because, in the 24-hour interval allowed, recordings returned to control levels. Reversal or randomisation of the order would have required an interval of at least several days and this was considered unjustified since the procedure already required two days of invasive monitoring.

While interpretation must, then, be cautious, the results give little support for the use of digitalis glycosides in patients with severe aortic regurgitation in the absence of a more specific indication such as atrial fibrillation with rapid ventricular response. It remains conjectural whether long-term vasodilator therapy will be beneficial in the patient group we studied, either in reducing symptoms or in slowing deterioration of ventricular function but, in principle, vasodilator therapy seems to be more soundly based than prophylactic digitalisation.

The authors are grateful to Mr L Mina for assistance with the statistical analysis of the results, and to AHS Australia Pty Ltd and the University of Western Australia for financial assistance.

\section{References}

${ }^{1}$ Corrigan DJ. On permanent patency of the mouth of the aorta or inadequacy of the aortic valves. Edinburgh Med Surg f 1832; 37: 225-45.

2Stewart HA. Experimental and clinical investigation of the pulse and blood pressure changes in aortic insufficiency. Arch Intern Med 1908; 1: 102-47.

${ }^{3}$ Kloster FE, Bristow JD, Lewis RP, Griswold HE. Pharmacodynamic studies in aortic regurgitation. $A m \mathcal{F}$ Cardiol 1967; 19: 644-52.

${ }^{4}$ Hopkins BE, Taylor RR. Digitalis induced increase in aortic regurgitation and the contrasting effects of glucagon in the sedated dog. 7 Clin Invest 1974; 53: 1716-25.

${ }^{5}$ Bolen JL, Alderman EL. Hemodynamic consequences of afterload reduction in patients with chronic aortic regurgitation. Circulation 1976; 53: 879-83.

${ }^{6}$ Miller RR, Vismara LA, deMaria AN, Salel AF, Mason DT. Afterload reduction therapy with nitroprusside in severe aortic regurgitation: improved cardiac performance and reduced regurgitant volume. Am $\mathcal{F}$ Cardiol 1976; 38: 564-7.

${ }^{7}$ Awan NA, Miller RR, Maxwell K, Mason DT. Comparative clinical effects of oral prazosin on the forearm resistance and capacitance vessels. Clin Pharmacol Ther 1977; 22: 79-84.

${ }^{8}$ Awan NA, Miller RR, DeMaria AW, Maxwell KS, Neumann A, Mason DT. Efficacy of ambulatory systemic vasodilator therapy with oral prazosin in chronic refractory heart failure. Circulation 1977; 56: 346-54.

${ }^{9}$ Awan NA, Miller RR, Mason DT. Comparison of effects of nitroprusside and prazosin on left ventricular function and the peripheral circulation in chronic refractory congestive heart failure. Circulation 1978; 57: 152-9.

${ }^{10}$ Feigenbaum H. Echocardiography. 2nd ed. Philadelphia: Lea \& Febiger, 1976: 73.

${ }^{11}$ Gorlin RC, McMillan IKR, Medd WE, Matthews BM, Daly R. Dynamics of the circulation in aortic valvular disease. Am f Med 1955; 18: 855-70.

${ }^{12}$ Brawley RK, Morrow AG. Direct determinations of aortic blood flow in patients with aortic regurgitation. Effects of alterations in heart rate, increased ventricular preload or afterload and isoproterenol. Circulation 1967; 35: 32-45.

${ }^{13}$ Ettinger PO, Frank MJ, Levinson GE. Hemodynamics at rest and during exercise in combined aortic stenosis and insufficiency. Circulation 1972; 45: 267-76.

${ }^{14}$ Hopkins BE, Taylor RR. Influence of various catechol- 
amines on aortic regurgitation. f Appl Physiol 1973; 34: $309-17$.

${ }^{15}$ Mehta M, Iacona M, Feldman RL, Pepine CH, Conti $\mathrm{CR}$. Comparative hemodynamic effects of intravenous nitroprusside and oral prazosin in refractory heart failure. $A m$ f Cardiol 1978; 41: 925-30.

${ }^{16}$ Rackley CE, Hood WP Jr, Rolett EL, Young DT. Left ventricular end-diastolic pressure in chronic heart disease. Am $\mathcal{F}$ Med 1970; 48: 310-9.

${ }^{17}$ DeMots H, Rahimtoola SH, McAnulty JH, Porter GA. Effects of ouabain on coronary and systemic vascular resistance and myocardial oxygen consumption in patients without heart failure. Am $\mathcal{F}$ Cardiol 1978; 41: 88-93.
${ }^{18}$ Moe GK, Farah AL. The pharmacological basis of therapeutics. 5th ed. New York: Macmillan, 1975.

${ }^{19}$ Mason DT, Braunwald E. Studies on digitalis X. Effects of ouabain on forearm vascular resistance and venous tone in normal subjects and in patients in heart failure. f Clin Invest 1964; 43: 532-43.

${ }^{20}$ Brogden RN, Heel RC, Speight TM, Avery GS. Prazosin: a review of its pharmacological properties and therapeutic efficacy in hypertension. Drugs 1977; 14: 163-97.

Requests for reprints to Professor Roger R Taylor, Department of Cardiology, Royal Perth Hospital, Perth, Western Australia 6000. 